\title{
A posição (realista ou
alista?) do Brasil em face da \\ A posição (realista ou
racionalista?) do Brasil em face da decisão da OMC
}

\section{The (REALISTIC OR RACIONALISTIC?) POSITION OF BRAZIL IN FACE OF WTO DECISION}

\author{
Gilberto Vaciles Bilacchi Junior *
}

Resumo: As tratativas entre os países que compõem a moderna sociedade internacional sempre foram marcadas por divergências e conflitos de interesses, especialmente âmbito das relações comerciais. A partir da análise da discussão travada entre o Brasil e os Estados Unidos da América perante a Organização Mundial do Comércio - OMC, e que culminou com a autorização do órgão internacional para que o nosso país adotasse medidas financeiras compensatórias aos prejuízos causados pelos subsídios agrícolas concedidos aos produtores norte-americanos, analisar-se-á, com base nas diferentes correntes teóricas do direito internacional, como se dá a tomada de decisões pelos países no âmbito das relações internacionais. Será dado destaque para a Escola das Três Tradições, que se baseia nos conceitos de Hedley Bull e Martin Wight de três tradições de ação no ambiente internacional.

Palavras-chave: Teorias das relações internacionais. Caso Brasil e EUA perante a OMC. Escola das três tradições.

Abstract: Negotiations between the countries that make up the modern international society have always been marked by disagreements and conflicts of interests, especially trade relations. From the analysis of the discussion held between Brazil and the United States before the World Trade Organization - WTO, and culminated with the authorization of the international governing body for our country to take measures financial compensation to the damage caused by agricultural subsidies to U.S. producers, will analyze, based on different theoretical perspectives of international law, as is the decisionmaking by countries in international relations. Emphasis will be placed for the School of the Three Traditions, which is based on the concepts of Hedley Bull and Martin Wight three traditions of action in the international environment.

Keywords: Theories of international relations. Where U.S. and Brazil before the WTO. School of three traditions.

\footnotetext{
* Advogado. Mestre em Direito das Relações Internacionais pelo Centro Universitário de Brasília - UniCEUB. E-mail: gilbertobilacchijr@gmail.com.
}

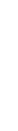




\section{INTRODUÇÃO}

O que se pretende por meio do presente artigo é analisar a decisão tomada pelo governo brasileiro que, embora tenha vencido a disputa comercial travada com os Estados Unidos da América perante a Organização Mundial do Comércio (OMC), optou por não exercer o seu direito de retaliar os produtos americanos de forma a obter a devida compensação financeira em decorrência dos incentivos financeiros concedidos aos produtores americanos de algodão.

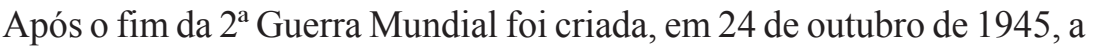
Organização das Nações Unidas (ONU), por meio da promulgação da Carta das Nações Unidas, que hoje inclui 193 estados-membros, e tem como foco de atuação a manutenção da paz e o desenvolvimento dos países, sendo que a Liga das Nações foi por ela substituída como entidade máxima e fórum da discussão do Direito internacional e dos entendimentos supranacionais (ORGANIZAÇÃO DAS NAÇÕES UNIDAS, 2011).

No âmbito do comércio internacional, é a Organização Mundial do Comércio (OMC) o órgão competente para gerenciar os acordos que compõem o sistema multilateral de comércio; servir de fórum para a celebração de pactos internacionais; e supervisionar a adoção dos tratados e a implementação das medidas pelos membros da organização. Outra função muito importante da entidade é o Sistema de Resolução de Controvérsias, que a destaca entre outras instituições internacionais. Este mecanismo foi criado para solucionar os conflitos gerados pela aplicação dos acordos sobre o comércio internacional entre os membros da OMC (THORSTENSEN; JANK, 2005, p.21).

Assim, não mais prevalecendo o uso da força militar, e estando constituídos os órgãos competentes para a resolução das divergências surgidas entre os países da sociedade internacional, teve início em 2003 a disputa comercial entre o Brasil e os Estados Unidos da América quando o Brasil acusou o governo americano de subsidiar a produção de algodão de seu país, ou seja, de fornecer ajuda financeira aos seus produtores para que a sua produção ficasse mais barata. Com essa atitude os fazendeiros norte-americanos se tornaram mais competitivos no mercado internacional, uma vez que conseguiam produzir a um custo menor, e causaram distorções nos preços do produto no mercado internacional, de forma a criar uma vantagem injusta em detrimento dos produtores de outros países (PORTAL R7 NOTÍCIAS, 2010).

Em 2005 a Organização Mundial do Comércio (OMC) decidiu que os americanos deveriam fazer ajustes administrativos nos programas de ajuda a 
seus produtores de algodão, ou suspender os créditos aos exportadores do produto. Nenhuma das alternativas foi implementada. Em março de 2006 o Brasil recorreu novamente à Organização do Comércio, sob o argumento de que a decisão não foi cumprida. O órgão voltou a condenar os americanos em janeiro de 2008 que, no mês seguinte, apelaram ao Órgão de Solução de Disputas - a instância da OMC que soluciona esse tipo de queixas, sendo a decisão foi mantida em junho de 2008.

Ao examinar de forma inédita a questão dos subsídios agrícolas no âmbito de seu mecanismo de solução de controvérsias, o painel do algodão da OMC, de acordo com o governo brasileiro, forneceu elementos valiosos para uma melhor compreensão e reforço das atuais disciplinas multilaterais do comércio agrícola. A decisão beneficiará a cotonicultura brasileira e alguns dos países mais pobres da África que produzem algodão, e que são bastante prejudicados pelos subsídios em questão, além de impulsionar o fim das distorções no comércio agrícola mundial (BRASIL, 2010).

A retaliação foi aprovada pela Organização Mundial, em novembro de 2009, como forma de punição aos excessivos gastos de Washington com o subsídio de seus produtores de algodão, e também por causa do programa de garantias para créditos a exportadores. Em contrapartida, o Brasil foi liberado para adotar tarifas e quebrar direitos de propriedade intelectual, até um total avaliado em 829 milhões de dólares.

A partir de então os governos de ambos os países litigantes iniciaram negociações a fim de se chegar a um acordo, que pudesse evitar a implementação das medidas sancionatórias pelo Brasil. Havido consenso, o Itamaraty informou que o acordo feito com os Estados Unidos irá beneficiar os produtores brasileiros de algodão, e que o Conselho de Ministros da Câmara de Comércio Exterior (Camex) aprovou o pacto que prevê o repasse de US\$ 147 milhões anuais a um fundo para o setor cotonicultor brasileiro, até que os norte-americanos aprovem uma nova lei agrícola. $\mathrm{O}$ ministro da Agricultura considerou um grande avanço o acerto com os EUA. Com o acordo, fica suspensa a sanção autorizada pela Organização Mundial do Comércio (OMC), até a aprovação da próxima lei agrícola americana.

Os EUA já deram início às audiências para votar uma nova lei agrícola sendo que, uma vez concluído o processo legislativo que colocará em vigor a nova lei agrícola norte-americana em 2012, as partes examinarão as modificações introduzidas pela novel lei estrangeira, e avaliarão a possibilidade de informar à 
OMC que foi alcançada uma solução mutuamente satisfatória para o contencioso (BRASIL, 2010).

Pelos fatos narrados, e conforme será visto a seguir, pode-se afirmar que a preferência do governo brasileiro pela realização de um acordo, e a escolha em não fazer cumprir a decisão da $\mathrm{OMC}$, que autorizou a majoração do percentual dos impostos sobre produtos importados dos EUA como forma de retaliação pela concessão de subsídios agrícolas aos produtores norte-americanos de algodão em detrimento dos produtores nacionais, foi uma escolha política, ou diplomática, contrária à decisão técnica e jurídica do órgão de solução de controvérsias da Organização Mundial do Comércio (OMC), mas que, segundo o entendimento das autoridades brasileiras, seria mais benéfica para o País.

\section{MUNDO JURÍDICO E MUNDO POLÍTICO}

Nestor Pedro Sagues fala da distinção entre o mundo jurídico e o mundo político. Afirma ele que determinados fenômenos são políticos e outros são jurídicos, e que essa diferenciação se explica por razões técnicas e éticas. Para ele quem se apresenta como homem do direito não lhe corresponde atuar como político. As razões jurídicas deveriam ser, portanto, impermeáveis as tentações políticas.

A “tese da distinção" se justifica por três razões principais, quais sejam: a) a existência de dois objetos distintos, o jurídico e o político; b) certa incompatibilidade entre tais esferas; c) e a supremacia moral do mundo jurídico sobre o mundo político, deixando entrever que o primeiro se preocupa mais que o segundo com a defesa da dignidade do homem. Em contrapartida, os críticos da visão de mundo jurídico e defensores do mundo político definem a tarefa jurídica como ofício burocrático, inimigo do rápido desenvolvimento de uma comunidade que aspira a um regime mais justo.

Resumindo, a crença da distinção entre o mundo político e o mundo jurídico parte do pressuposto de que determinados casos são de natureza política e outros, distintos dos anteriores, são de natureza jurídica. Consequentemente, o homem poderá atuar juridicamente em determinado momento e politicamente em outro. (SAGUES, 1978, p.1-3, tradução nossa).

Para o referido autor, existem quatro posturas fundamentais acerca do tema. A primeira seria a "tese da dualidade" dos valores jurídicos e dos valores políticos, havendo valores específicos para o direito e valores próprios para a 
política; a segunda fala da "coincidência parcial dos valores jurídicos e políticos"; a terceira seria a tese da "coincidência dos valores jurídicos e politicos, mas com diferenciação em sua operatividade"; e a quarta e última tese trata da "unidade" clara dos valores jurídicos e políticos, condicionada sua operatividade às necessidades do homem (SAGUÉS, 1978, p.242-243). Entretanto, as discussões mais acaloradas restringem-se apenas em torno de duas posições fundamentais, a da dualidade e a da unidade, que se contrapõem acerca do tema mundo jurídico e mundo político.

De acordo com o atual estágio de desenvolvimento das relações internacionais, cada país tem a liberdade de estabelecer suas próprias linhas ideológicas e de conduta. O Brasil optou, politicamente, pela realização de um acordo que viesse a satisfazer suas pretensões, ainda que parcialmente, mas que evitasse uma disputa comercial com os EUA e pudesse contaminar outras áreas do comércio bilateral entre os dois países.

Vista a diferença doutrinária entre mundo político e mundo jurídico, será agora este último explorado de forma mais aprofundada, sob a ótica das relações internacionais.

\section{AS RELAÇÕES INTERNACIONAIS}

Como visto, atualmente a Organização das Nações Unidas (ONU) reconhece a existência de 193 Estados soberanos. Além dos países-membros, outros agentes são reconhecidos pela sociedade internacional. Da interação desses agentes advém um inter-relacionamento no âmbito internacional que é o objeto de estudo das Relações Internacionais.

Relações Internacionais é o estudo das interações entre os vários protagonistas que participam da política internacional, incluindo Estados, organizações internacionais, organizações não-governamentais, entidades sub-nacionais, como burocracias e governos locais, e indivíduos. É o estudo dos comportamentos desses protagonistas quando participam individualmente ou junto dos processos políticos internacionais (MINGST, 2009, p.2).

O ponto de partida das relações internacionais é a existência de Estados, que são comunidades políticas independentes onde cada uma delas possui seu próprio governo e afirma a sua soberania com relação a um determinado território e a um segmento da população. 
A soberania é a característica principal de um Estado para que ele possa figurar na sociedade internacional e manter relações com outros agentes desta sociedade. De um lado temos a soberania interna de um Estado, que se dá em relação ao seu território e sua população, exercendo a supremacia sobre todas as demais autoridades dentro daquele território e em respeito a essa população; de outro temos a soberania externa, que consiste não na supremacia, mas na independência do Estado com respeito às autoridades externas (BULL, 2002, p.13)".

Assim, para que as relações internacionais se desenvolvam e atinjam seus objetivos, faz-se necessário o estabelecimento de uma ordem na sociedade internacional. Afirma Hedley Bull $(2002$, p. 8) que essa “ordem que se procura na vida social não é qualquer ordem ou regularidade nas relações entre indivíduos ou grupos, mas uma estrutura de conduta que leve a um resultado particular, um arranjo da vida social que promova determinadas metas ou valores."

O autor identifica quatro dessas metas ou valores: a) a preservação da sociedade internacional; b) a defesa da independência dos Estados membros; c) a manutenção da paz; e d) a ajuda na garantia das fundações normativas de toda a vida social, como a limitação da violência e a estabilidade dos bens (JACKSON; SORENSEN, 2007, p.212).

Nesse sentido podemos dizer que temos dois tipos de ordem: a ordem mundial e a ordem internacional. Por ordem mundial entendemos os padrões ou disposições da atividade humana que sustentam os objetivos elementares ou primários da vida social na humanidade considerada em conjunto. Por ordem internacional podemos compreender um padrão de atividade que sustenta os objetivos elementares ou primários da sociedade dos estados, ou sociedade internacional (BULL, 2002, p.23-26).

Desse modo, verificamos que a ordem mundial é mais ampla do que a ordem internacional, porque para descrevê-la precisamos tratar não só da ordem entre os Estados, mas também da ordem em escala interna ou local, existente dentro de cada Estado. Também a ordem mundial precede moralmente a ordem internacional, pois é a ordem em toda a humanidade que precisamos considerar como tendo valor primário, não a ordem dentro de uma específica sociedade de Estados.

A partir do final do século XIX e início do século XX, surgiu pela primeira vez um sistema singular verdadeiramente universal. A ordem em escala global deixou de ser simplesmente o somatório dos vários sistemas políticos que produziam a ordem em escala local, ou seja, no âmbito interno dos países; ele é 
também o resultado do que se poderia chamar de sistema político mundial. O primeiro sistema político mundial assumiu a forma de um sistema de estados de âmbito global.

Para uma melhor compreensão, vejamos a definição de sistema de estados e sociedade de estados dada por Hedley Bull.

Sistema de estados (ou sistema internacional) se forma quando dois ou mais estados têm suficiente contato entre si, com suficiente impacto nas suas decisões, de tal forma que se conduzam, pelo menos até certo ponto, como partes de um todo. Existe uma sociedade de estados (ou sociedade internacional) quando um grupo de Estados, conscientes de certos valores e interesses comuns, formam uma sociedade, no sentido de se considerarem ligados, no seu relacionamento, por um conjunto comum de regras, e participam de instituições comuns (BULL, 2002, p.15-19).

Assim, podemos concluir que as relações internacionais partem de um princípio de ordem, que por sua vez regula um sistema de estados que abrange as sociedades de estados. Essa sociedade de estados, embora vigore em um regime de "anarquia internacional", mantém certo grau de ordem pelos seguintes elementos: a) interesses em comum, com a percepção de elementos e princípios comuns à ordem de Estados; b) regras, que estão refletidas no Direito Internacional e nada mais são do que a manifestação formal dos interesses comuns dos Estados e servem, portanto, de orientação para as ações estatais; e c) instituições, que tem o papel de garantir a eficácia das regras internacionais.

Visando uma melhor compreensão do complexo campo teórico das relações internacionais, faremos a seguir uma sucinta explanação acerca das principais correntes filosóficas da teoria das relações internacionais.

\section{AS TEORIAS DAS RELAÇÕES INTERNACIONAIS}

As teorias de relações internacionais são bastante diversificadas e podem ser classificadas de formas diferentes. Para se ter uma idéia, desde o final da Primeira Guerra Mundial já houveram três grandes debates acadêmicos dos teóricos das relações internacionais. O primeiro grande debate foi entre o liberalismo utópico e o realismo; o segundo entre as abordagens tradicionais e o behaviorismo; o terceiro entre o neo-realismo e o neo-marxismo; e agora estamos entrando no quarto debate. É fundamental nos familiarizarmos com a evolução 
teórica da disciplina de relações internacionais para que possamos melhor entender suas direções atuais e futuras. Eis as principais correntes teóricas:

\subsection{Liberalismo}

O Liberalismo tem raízes históricas em várias tradições filosóficas que postularam ser a natureza humana basicamente boa. Indivíduos formam grupos e, mais tarde, Estados. Em geral, os Estados cooperam e seguem normas e procedimentos internacionais com os quais concordam. De acordo com a visão liberal, os homens são racionais, e aplicadas a razão às relações internacionais, podem estabelecer organizações capazes de gerar benefícios a todos (JACKSON; SORENSEN, 2007, p.64-65).

\subsection{Realismo}

O Realismo postula que os Estados existem em um sistema internacional anárquico, onde cada Estado baseia suas políticas em uma interpretação de interesses nacionais definida em termos de poder. A estrutura do sistema internacional é determinada pela distribuição de poder entre os Estados. Assim, as relações internacionais seriam, em um sentido básico, a luta entre desejos e interesses conflitantes, que envolvem muito mais a rivalidade do que a cooperação. Para Hans J. Morgenthau, "a natureza humana é a base das relações internacionais, e como os seres humanos buscam seus próprios interesses e poder, agressões ocorrem com facilidade (JACKSON; SORENSEN, 2007, p.69-72)".

Essas duas correntes teóricas, também denominadas teorias clássicas, proporcionaram o primeiro grande debate acadêmico das Relações Internacionais, sagrando-se o Realismo vencedor por ter prevalecido na maior parte do século XX.

\subsection{Teoria radical}

Em uma terceira abordagem surge a Teoria Radical, segundo a qual as ações dos indivíduos são determinadas em grande parte pela classe econômica. Afirmam que o Estado é um agente do capitalismo internacional e o sistema internacional é altamente estratificado, sendo dominado por um sistema capitalista internacional. Dentro dessa teoria encontramos o pós-modernismo e o 
construtivismo, ambos generalizados da investigação de todas as interações sociais.

O pós-modernismo questiona toda noção de Estado pelo fato de o considerarem uma ficção engendrada por eruditos e cidadãos. Afirmam os teóricos dessa corrente doutrinária que os Estados não agem de modo regularizado, mas são conhecidos apenas pelas histórias que se contam sobre eles, filtradas pelas perspectivas de quem as conta. Por isso a tarefa da análise pós-modernista é desconstruir os conceitos básicos da área e substituí-los por múltiplas realidades. Já os construtivistas argumentam que as estruturas fundamentais no sistema de Estados não são materiais, mas intersubjetivas e sociais. Para eles, o interesse dos Estados não é fixo, mas maleável e em eterna mutação. Compartilham a crença comum de que o discurso modela o comportamento dos protagonistas políticos e, com eles, definem interesses. Esta teoria vem conquistando importância crescente no pensamento das relações internacionais no século XXI (MINGST, 2009, p.2-3).

Após o primeiro debate das correntes teóricas das relações internacionais travado entre a escola liberal e a escola realista, e o segundo grande debate travado entre as abordagens metodológicas behaviorista e tradicional ${ }^{1}$, surge $o$ terceiro grande debate que transfere o foco das questões militares e políticas para os aspectos econômicos e sociais, e introduz problemas socioeconômicos de bem-estar, político militares e de segurança presentes nos países do Terceiro Mundo (JACKSON; SORENSEN, 2007, p.76).

\subsection{Economia política internacional}

Podemos dizer que o objetivo dos pensadores dessa corrente filosófica é tratar do debate entre a riqueza e a pobreza internacional, com foco no desenvolvimento dos países subdesenvolvidos. O debate é travado por meio das correntes neomarxista, neoliberal e neorealista.

Os neomarxistas, baseados nos conceitos de exploração e opressão da classe trabalhadora (proletariado) pela classe capitalista (burguesia) desenvolvidos por Karl Marx, estendem essa análise para os países do Terceiro Mundo sob o argumento de que a economia capitalista global, controlada pelos Estados capitalistas ricos, é utilizada para enfraquecer os países mais pobres.

\footnotetext{
${ }^{1}$ A abordagem das relações internacionais pela perspectiva tradicional envolve o acadêmico no entendimento da história e da prática da diplomacia, da história e do papel do direito internacional, da teoria política do Estado soberano, e assim por diante. A behaviorista não inclui a moralidade nem a ética no estudo das relações internacionais, porque envolvem valores e não podem ser estudadas de forma objetiva, isto é, científica.
}

SCIENTIA IURIS, Londrina, v.16, n.1, p.195-210, jul.2012 
Os neoliberais, por outro lado, entendem que a prosperidade humana pode ser alcançada por meio da livre expansão global do capitalismo além das fronteiras do Estado soberano, e por meio do declínio da importância desses limites territoriais. Baseiam-se nos ensinamentos doutrinários de Adam Smith e outros economistas liberais clássicos que defendem serem os mercados livres, e que a propriedade privada e a liberdade individual criam a base para o progresso econômico auto-sustentável de todos os envolvidos (JACKSON; SORENSEN, 2007, p.89-90).

Ainda, a visão neorealista, fundamentada no pensamento do economista alemão Friedrich List, tem por base a idéia de que a atividade econômica deve se dedicar à construção de um estado forte e ao apoio do interesse nacional. Seguindo essa linha de pensamento, a riqueza deve ser controlada e administrada pelo Estado. Referida doutrina estadista é também chamada por muitos de mercantilismo ou nacionalismo econômico.

Entretanto, como visto, as três perspectivas da Escola da Economia Política Internacional discordam entre si em termos de conceitos e valores, e assumem visões fundamentalmente diferentes acerca da economia política internacional, o que resulta na ausência de uma perspectiva predominante e que possa ser considerada vencedora do terceiro grande debates das relações internacionais.

Analisados, ainda que brevemente, algumas das principais correntes teóricas das relações internacionais, passemos à análise da Escola das Três Tradições.

\section{A ESCOLA DAS TRÊS TRADIÇÕES ${ }^{2}$}

A Escola das Três Tradições constitui uma abordagem de índole interpretativista e pluralista à Teoria das Relações Internacionais, que se centra nos conceitos de Hedley Bull e Martin Wight de três tradições de ação no ambiente internacional. De acordo com as palavras de Samuel Pires, "constitui uma revigorante visão de mundo para aqueles que não se identificam nos diversos pólos dos debates decorrentes da academia norte-americana, liderados pelo liberalismo e realismo (PIRES, 2009)".

\footnotetext{
${ }^{2}$ Essa denominação prevaleceu por ser a que mais se ajusta ao contexto dessa teoria das relações internacionais. Sociedade Internacional faz referencia direta à teoria racionalista, enquanto que Escola Inglesa foi descartado por serem seus principais teóricos provenientes de outros países que não a Inglaterra.
} 
Historicamente, pode-se dizer que durante as décadas de 1950 e 1960 o meio academio norte-americano dominou os ensinamentos da disciplina de relações internacionais. Entretanto, no período da Guerra Fria surgiu uma escola inglesa com enfoque na abordagem tradicional e baseada no entendimento humano, no julgamento, nas normas e na história, que negava qualquer distinção severa entre as rígidas visões realista e liberal das relações internacionais.

A escola da sociedade internacional é uma abordagem histórica e institucional da política mundial com ênfase nos seres humanos e em seus valores políticos. (...) Os estudiosos da sociedade internacional, no entanto, argumentam que a política mundial é uma sociedade anárquica com instituições, normas e regras distintas utilizadas pelos políticos para conduzir a política externa (JACKSON; SORENSEN, 2007, p.195).

A Escola das Três Tradições é uma das abordagens de relações internacionais clássicas que busca uma posição intermediária entre as escolas do realismo e do liberalismo. Por um lado, seus autores recusam a visão singular e pessimista dos Estados como organizações políticas auto-suficientes e orgulhosas, que se relacionam e lidam uns com os outros apenas por interesses próprios capazes de gerar a guerra, sugerida pela escola realista. Por outro lado, rejeitam a abordagem otimista do liberalismo das relações internacionais como uma comunidade mundial em desenvolvimento que leva ao progresso humano e à paz perpétua.

Os teóricos da Escola das Três Tradições consideram os Estados como a base da política mundial, uma vez que as relações internacionais consistem em políticas, decisões e atividades voltadas ao âmbito global e realizadas por estadistas que agem em nome dos Estados soberanos. Desse modo, encontramse os Estados concebidos como organizações humanas, ficando que o conceito fundamental da teoria é o de uma sociedade de Estados (JACKSON; SORENSEN, 2007, p.196).

São conceitos centrais da teoria das três tradições, o sistema de estados, proveniente do realismo, e o conceito de sociedade de estados, originário do liberalismo, conforme segue:

Sistema de estados (ou sistema internacional) se forma quando dois ou mais estados têm suficiente contato entre si, com suficiente impacto nas suas decisões, de tal forma que se conduzam, pelo menos até certo ponto, como partes de um todo. Existe uma sociedade de estados (ou sociedade 
internacional) quando um grupo de Estados, consciente de certos valores e interesses comuns, formam uma sociedade, no sentido de se considerarem ligados, no seu relacionamento, por um conjunto comum de regras, e participam de instituições comuns (BULL, 2002, p.15-19).

Uma vez que na política internacional não há uma autoridade hierárquica, não há um governo mundial acima dos Estados soberanos, mas, no entanto, ainda existem interesses, regras, instituições e organizações comuns criados pelos estados para ajudar a constituir a interação entre eles, Hedley Bull (2002, p.57) define a condição internacional como uma sociedade anárquica:

Sustenta-se em geral que a existência da sociedade internacional é desmentida em razão da anarquia, ou seja, da ausência de um governo ou de regras. É óbvio que, ao contrário dos indivíduos que vivem no seu interior, os estados soberanos não estão sujeitos a um governo comum, e que neste sentido existe uma anarquia internacional.

Martin Wight nos ensina que as idéias dos principais teóricos das relações internacionais se inserem em três categorias básicas: o realismo, o racionalismo e o revolucionismo - também denominadas de "três erres" (SARFATI, 2005, p.126). Segundo ele, somente a união dos conceitos dessas três "vozes" da Escola Inglesa é que poderia resultar em uma correta avaliação das relações internacionais. Segue a definição de cada um desses conceitos:

O realismo é o conceito no qual predomina a "anarquia internacional", e onde a rivalidade e o conflito entre os Estados são "inerentes" às suas relações. Nesse sentido, o elemento da anarquia, da política de poder e do conflito armado são enfatizados. Tal perspectiva se concentra no real, o que é, em detrimento do ideal, o que deveria ser. Portanto, rejeita um pensamento ilusório e a aceitação sincera do lado desagradável da vida. Quando levado ao extremo, o realismo é a negação da possibilidade de uma sociedade internacional, sendo que o que existe é um Estado de natureza hobbesiano. A única sociedade política e, de fato, comunidade moral é o Estado, logo não há obrigações internacionais além ou entre Estados. Os principais teóricos dessa teoria foram Nicolau Maquiavel e Thomas Hobbes.

O racionalismo acredita que os seres humanos são racionais e podem reconhecer o certo e aprender com seus erros e com os dos outros. Para os seus teóricos, as pessoas são capazes de viver de modo lógico e em conjunto, mesmo quando não há um governo comum, como na condição anárquica descrita 
pelos realistas. Levado ao extremo, o mundo dos racionalistas seria um mundo perfeito de respeito mútuo, concordância e do estado de direito entre os Estados. Dessa forma, essa perspectiva define um "caminho intermediário" da política internacional, situando-se entre os realistas pessimistas e os revolucionistas. Seu principal defensor foi Grotius (JACKSON; SORENSEN, 2007, p.204-205).

Os seguidores dessa teoria vêem o mundo como uma sociedade internacional, na qual ocorre a institucionalização de interesses e identidades partilhadas entre Estados, pelo qual o racionalismo se preocupa essencialmente com a criação e manutenção de normas partilhadas, regras e instituições, através de uma visão do Direito Internacional baseada na grociana combinação entre direito natural e direito positivo (PIRES, 2009).

Por sua vez, os defensores do revolucionismo são acadêmicos que se identificam com a humanidade e acreditam na "unidade moral" da sociedade além do Estado. A sua teoria internacional tem um caráter progressivo, e até mesmo missionário, por pretender mudar o mundo para melhor, sendo que, para eles, a mudança social revolucionária é o objetivo. Vislumbram o surgimento de um mundo ideal. Diferentemente dos realistas, os revolucionistas são otimistas com relação à natureza e acreditam na perfeição humana. Para eles, o propósito definitivo da história internacional é permitir que os homens alcancem a realização e a liberdade. Levado ao extremo, o revolucionismo seria uma reivindicação de que a única sociedade real na Terra é uma sociedade mundial composta de todos os seres humanos. Seu principal teórico foi Immanuel Kant (JACKSON; SORENSEN, 2007, p.205-206).

Wight fala também da distinção entre o realismo moderado e o realismo apropriado e extremado. Afirma que os realistas extremos negam a existência de uma sociedade internacional, pois consideram as relações internacionais entre Estados soberanos uma condição moralmente neutra e, dessa forma, instrumental. Para eles, a sociedade é possível dentro dos Estados, mas não entre eles, sendo que nenhum deles tem autoridade suficiente para controlar qualquer outro Estado soberano, e nenhum Estado Soberano tem a obrigação de obedecer a outro Estado soberano. Já os realistas moderados estão mais próximos dos racionalistas por reconhecerem o direito internacional, mas ressaltam que tais normas são elaboradas com base nos interesses e nas responsabilidades das grandes potências (JACKSON; SORENSEN, 2007, p.206-208).

Entretanto, Wight não faz nenhuma distinção importante dentro do racionalismo. Limita-se a reconhecer a importância norteadora do interesse 
nacional na conduta da política externa, ressaltando a legitimidade do interesse nacional de outros países e não simplesmente do seu próprio Estado, incluindo rivais e até inimigos.

\section{CONCLUSÃO}

Transportando as teorias abordadas para o âmbito deste trabalho, podese dizer que não existem dúvidas acerca da importância histórica da decisão do órgão de solução de controvérsias da Organização Mundial do Comércio (OMC) em permitir ao Brasil exercer o direito de retaliar os produtos importados dos Estados Unidos, seja por meio de elevação das alíquotas do imposto de importação, seja por meio da quebra de patentes de produtos industrializados, ou qualquer outra forma de compensação financeira, em decorrência da declaração de ilegalidade dos subsídios concedidos aos produtores norteamericanos de algodão. A decisão, sem dúvidas, servirá de orientação para disputas que versem sobre o cumprimento dos tratados e das regras comerciais regidas pelo Direito Internacional.

A opção do governo brasileiro de não exercer o direito de retaliação e celebrar um acordo com o governo americano é uma decisão eminentemente política, que foi considerada mais benéfica aos produtores brasileiros e às relações comerciais que envolvem Brasil e Estados Unidos. Conforme determina a Constituição da República Federativa do Brasil, por força do artigo 84, incisos VII e VIII, é competência privativa do Presidente da República manter relações com Estados estrangeiros e celebrar tratados, convenções e atos internacionais. Também compete ao Chefe do Poder Executivo ditar os rumos da economia nacional.

Entretanto, do ponto de vista teórico do Direito internacional, conclui-se que a concessão de subsídios financeiros aos produtores norte-americanos de algodão, por parte de seu governo, caracteriza o realismo descrito pela Escola das Três Tradições acima estudada, em que prevalece o egoísmo e a rivalidade entre os Estados soberanos, visando cada um obter maiores vantagens para si, ainda que em detrimento dos demais países da sociedade internacional.

Por outro lado, a decisão do governo brasileiro em realizar um acordo com o governo americano visando uma solução, ainda que provisória e dependente de condição futura - que será a aprovação pelo Congresso americano de reforma da lei de concessão de subsídios aos produtores de algodão -, caracteriza o racionalismo descrito pela Escola das Três Tradições. O Brasil 
parece buscar uma solução "amigável" e racional para que o consenso seja atingido, e não haja a instauração de um novo processo contencioso no âmbito das relações comerciais entre os países.

Almeja-se acreditar que a real intenção do governo brasileiro seja a obtenção de um acordo harmonioso entre os Estados litigantes, nos moldes da teoria racionalista. Todavia, sem querer demonstrar qualquer pessimismo extremado, parece é que o Brasil optou pela teoria realista ao não exercer seu direito de retaliação aos produtos americanos por uma causa óbvia - evitar o uso da força da economia americana em detrimento da economia brasileira no mercado internacional, ou seja, o boicote internacional dos produtos brasileiros por imposição do governo dos Estados Unidos da América.

\section{REFERÊNCIAS}

BRASIL. Constituição (1988). Constituição da República Federativa do Brasil. Brasília: Senado Federal, 2010.

BRASIL. Ministério das Relações Exteriores. 2004. Disponível em: <http:// www.itamaraty.gov.br/sala-de-imprensa/notas-a-imprensa/2004/08/estadosunidos-subsidios-ao-algodao > . Acesso em: set. 2010.

BRASIL. Ministério das Relações Exteriores. 2010. Disponível em: <http:// www.itamaraty.gov.br/sala-de-imprensa/selecao-diaria-de-noticias/midiainternacional/reino-unido/agencia-reuters/2010/06/18/brasil-adia-ate-2012retaliacao-aos-eua-sobre-algodao/?searchterm=algodão $>$.

Acesso em: set. 2010.

BULL, Hedley. A sociedade anárquica. Brasília: Editora Universidade de Brasília, 2002.

JACKSON, Robert. SORENSEN,Georg. Introdução às Relações Internacionais. Rio de Janeiro: Jorge Zahar Editor, 2007.

MINGST, Karen A. Princípios de relações internacionais. Tradução de Arlete Símile Marques. Rio de Janeiro: Elsevier, 2009.

ORGANIZAÇÃO DAS NAÇÕES UNIDAS. 2011. Disponível em: < http:// www.onu-brasil.org.br/conheca_hist.php>. Acesso em: 05 mai. 2012. 
PIRES, Samuel. As Três Tradições da Escola Inglesa de Relações Internacionais. Disponível em: $<$ http://nostrumtempus.blogspot.com/2009/ 01/symposium-as-trs-tradies-da-escola.html>. Acesso em set. 2010.

PORTAL R7 NOTÍCIAS. Entenda a disputa entre Brasil e EUA sobre o algodão: questionamento sobre subsídio começou em 2003 junto à Organização Mundial do Comércio. 2010. Disponível em: $<$ http:// noticias.r7.com/economia/noticias/entenda-a-disputa-entre-brasil-e-euasobre-o-algodao-20100308.html>. Acesso em: set. 2010.

SAGUÉS, Nestor Pedro. Mundo Jurídico y Mundo Político. Buenos Aires: Ediciones Depalma, 1978.

SARFATI, Gilberto. Teoria das relações internacionais. São Paulo: Saraiva, 2005.

THORSTENSEN, Vera; JANK, Marcos. O Brasil e os Grandes Temas do Comércio Internacional. São Paulo: Aduaneiras, 2005. p.21.

Recebido em: 2011-04-28 Aprovado para publicação em: 2012-05-15

Como citar: JUNIOR, Gilberto Vaciles Bilacchi. A posição (realista ou racionalista?) do Brasil em face da decisão da OMC. Scientia Iuris, Londrina, v.16, n.1, p.195-210, jul.2012. DOI: $10.5433 / 2178-8189.2012 v 16 n 1 p 195$. 